Journal of Aafiyah Health Research (JAHR)

P-ISSN: 2722-4929 \& E-ISSN: 2722-4945

Published by Postgraduate Program in Public health, Muslim University of Indonesia

Original Research Open Access

\title{
Ritual Pammungkara jodoh Terhadap Pernikahan Dini Di Kabupaten Jeneponto Tahun 2020
}

\author{
*Dewi ${ }^{1}$, Fatma Afrianty Gobel ${ }^{1}$, Muh. Khidri Alwi, Een Kurnaesih ${ }^{1}$ \\ ${ }^{1}$ Program Pascasarjana Kesehatan Masyarakat, Universitas Muslim Indonesia \\ *Email: dewidgnini@gmail.com
}

\begin{abstract}
Introduction: The marriage ceremony for early marriage is a custom practiced by people from ancient times so that it is hereditary that until now the community still performs such rituals, but the influence of the culture that exists in the village of Maccini wedge Jeneponto district is a complicated problem, many things are related there therefore this issue really needs special attention by people who are aware of it, because it harms adolescents and destroys the future of adolescents who do pammungkara soul mate rituals, because after that the teenagers will get married under age who are not yet physically ready, but because there are many factors that influence the parents to bring their children to impress when they are 15 years old, including cultural factors that are still closely in the village and they trust sanro for their power, followed by economic factors of the underprivileged who only expect average annual agricultural output, andlow education so that their knowledge will be less impact and the dangers of adolescents who engage in early marriage but the community does not understand that they consider themselves to be out of responsibility if their daughters are married, lack of religious knowledge also affects the occurrence of a pammungkara soul mate ritual even they justify that sanro gets strength because it is given Grace to Allah SWT. The purpose of this study was to analyze the Pammungkara jodoh Ritual for early marriage in the Jeneponto Regency. Method: This type of research is a qualitative research using a phenomology approach, to explore the phenomenon of pammungkara soul mate rituals towards early marriage in Jeneponto district through independent observation and interviews during the study. Results: The results of the pammungkara soul mate ritual research on early marriage that many factors influence adolescents to do the matchmaking, but the most triggering and influential factors are cultural factors that are still high and the economy is lacking, low knowledge, and lack of belief in God triggers The community performs a pammungkara soul mate ritual towards early marriage in Jeneponto Regency.
\end{abstract}

Keywords: Pammukara Jodoh, Marriage, Teenagers. 


\begin{abstract}
ABSTRAK
Pengantar: Ritual Pammungkara jodoh terhadap pernikahan dini merupakan kebiasaan yang dilakukan oleh masyarakat dari zaman dahulu sehingga bersifat turun temurun yang sampai sekarang masyarakat masih melakukan ritual seperti itu. Pengaruh dari budaya yang ada di Desa Maccini Baji Kabupaten Jeneponto adalah masalah yang rumit, banyak hal yang berhubungan di sana, oleh karena itu masalah ini sangat perlu perhatian khusus oleh masyarakat yang sadar akan hal itu, karena merugikan remaja dan menghancurkan masa depan remaja, karena selepas itu remaja tersebut akan menikah di bawah umur yang secara fisiologis belum siap, tetapi karena banyak faktor yang mempengaruhi sehingga para orang tua membawa anaknya ke sanro jika sudah berumur 15 tahun, termasuk faktor budaya yang masih erat di desa dan mereka mempercayai sanro akan kekuatannya, ditambah lagi faktor ekonomi mereka yang kurang mampu yang hanya rata-rata mengharapkan hasil bumi pertahun, dan pendidikan rendah sehingga pengetahuan mereka kurang akan dampak dan bahayanya remaja yang melakukan pernikahan dini tetapi masyarakat tidak paham akan hal itu, bahkan mereka menganggap dirinya sudah lepas tanggung jawab jika anak putrinya sudah menikah, kurangnya ilmu agama juga mempengaruhi terjadinya ritual pammungkara jodoh bahkan mereka membenarkan bahwa Sanro mendapatkan kekuatan karena diberikan Rahmat oleh Allah SWT. Tujuan penelitian ini dilakukan untuk menganalisa Ritual Pammungkara jodoh terhadap pernikahan dini di Kabupaten Jeneponto. Metode: Jenis penelitian adalah penelitian kualitatif dengan pendekatan fenomologi untuk mengeksplorasi mengenai fenomena Ritual Pammungkara jodoh terhadap pernikahan dini di Kabupaten Jeneponto melalui observasi indepeth dan interview selama penelitian berlangsung. Hasil: Hasil penelitian diperoleh bahwa banyak faktor yang mempengaruhi remaja melakukan Ritual Pammungkara jodoh terhadap pernikahan dini di Kabupaten Jeneponto antara lain: Pengaruh budaya yang masih kuat, tingkat ekonomi yang rendah, Pengetahuan rendah, dan kurangnya keyakinan kepada Allah SWT.
\end{abstract}

Kata Kunci: Pammukara Jodoh, Pernikahan, Remaja.

\section{PENDAHULUAN}

Awal terjadinya ritual Pammungkara jodoh di Desa Maccini Baji Kabupaten Jeneponto, bermula sejak zaman dahulu secara turun temurun ke ibu dan ketika ibunya meninggal barulah beliau melanjutkan ritual tersebut, karena masyarakat juga percaya akan kekuatan sanro maka berawal dari situlah orang berdatangan apalagi mereka sudah melihat bukti setelah dimandi oleh sanro salah satu remaja yang datang ke rumahnya yang sudah melakukan ritual pammungkara jodoh tidak lama setelah itu remaja tersebut menikah, dilihat dari budaya masyarakat setempat yang masih kental dan takut dipermalukan (dipakasiri) sama anaknya menjadi alasan juga bagi masyarakat untuk melihat anaknya cepat menikah (1), dimana kita ketahui bahwa pernikahan menjadi hal atau agenda penting bagi manusia, hal ini dikarenakan dengan menikah seseorang akan memperoleh keseimbangan hidup, baik secara biologis, psikologis maupun secara sosial. Seseorang yang melangsungkan pernikahan, maka semua kebutuhan biologisnya dapat terpenuhi. Namun dalam pelaksanaannya, diperlukan kematangan emosi dan kedewasaan sehingga kelangsungan pernikahannya dapat terjaga dengan baik (2)

Pola perilaku budaya yang diturunkan dari generasi ke generasi memberikan kerangka kerja konseptual untuk memahami esensi dari semua perilaku manusia, dukun atau Sandro masih dipercaya oleh masyarakat dapat menyelesaikan segala permasalahan yang dihadapi. (3) 
Penyebab pernikahan usia dini antara lain pemaksaan dari pihak orang tua, pergaulan bebas, rasa keingintahuan tentang dunia seks, faktor lingkungan, rendahnya pendidikan, faktor ekonomi. Ditinjau dari masalah sosial ekonomi adalah pernikahan usia dini biasanya tidak diikuti dengan kesiapan keadaan ekonomi. (4) Semakin bertambah umur seseorang kemungkinan untuk kematangan dalam bidang sosial ekonomi juga akan semakin nyata karena pada umumnya dengan bertambahnya umur akan semakin kuat dorongan untuk mencari nafkah penopang. (5)

Pada pernikahan usia dini permasalahan ekonomi akan menjadi alasan utama terjadinya perceraian. Sanro mengatakan bahwa ritual pammungkara jodoh ini dilakukan pada remaja yang betul-betul percaya akan hal tersebut karena menurut beliau kepercayaan adalah kunci dari keberhasilan ritual ini. Jadi yang datang kepada sanro baik remaja atau orang tua remaja yang ingin melihat anaknya cepat menikah agar percaya betul dan yakin bahwa ritual ini akan berhasil. (6) Dan juga dilengkapi dengan syarat syarat yang sudah ditentukan sebelumnya seperti: Sarung Sikasalingan Burakne, dimana sanro meyakini bahwa sarung ini persyaratan untuk memikat hati laki laki, Kembang suci (bunga melati, bunga mawar dan bunga kenanga). Ini digunakan untuk memandikan perempuan agar perempuan yang sudah dimandikan dengan bunga tersebut agar selalu terlihat cantik dan bersinar dimata lelaki Air aqua dalam botol Air dalam botol yang sudah dibacakan mantra dan ditiup-tiup oleh sanro, air ini diminum perempuan pada malam hari sebelum tidur yang diyakinin dapat menangkat guna-guna atau santet dari orang yang jahat, Ayam Kampung Jantan 1 ekor sebagai salah satu syarat agar berhasilnya ritual tersebut Mahar, mahar diberikan sebagai tanda terimakasih kepada sanro/dukun yang sudah membantu melaksanakan ritual pammungkara jodoh yang sudah membantu untuk segera menikah .(7)

Pernikahan dini merugikan remaja dan menghancurkan masa depan remaja remaja yang melakukan ritual pammungkara jodoh, karena selepas itu remaja tersebut akan menikah dibawah umur yang secara fsiologis belum siap, tetapi karena banyak faktor yang mempengaruhi sehingga para orang tua membawa anaknya kesanro (8). Penelitian ini bertujuan untuk mengetahui faktor penyebab Ritual Pammungkara jodoh terhadap pernikahan dini dalam segi budaya, ekonomi, pengetahuan dan keyakinan dalam hal ritual pammungkara jodoh terhadap pernikahan dini di Kabupaten Jeneponto.

\section{METODE PENELITIAN}

Penelitian ini menggunakan pendekatan penelitian kualitatif yaitu penelitian yang bermaksud untuk memahami fenomena tentang apa yang dialami subyek penelitian, dengan cara deskripsi dalam bentuk kata-kata dan bahasa, pada suatu konteks khusus yang mengeksplorasi mengenai fenomena ritual pammungkara jodoh terhadap pernikahan dini di Kabupaten Jeneponto.

\section{HASIL}

Penelitian ini dilaksanakan bulan Mei 2020 di Kabupaten Jeneponto. Subjek dalam penelitian ini adalah remaja yang melakukan Ritual Pammungkara jodoh terhadap pernikahan dini, remaja yang melakukan pernikahan dini sebanyak sebanyak 10 orang yang ada di Desa Maccini Baji . 
Tabel 1. Data Responden

\begin{tabular}{cccccc}
\hline No & Inisial Informan & Umur & Pendidikan & Jenis kelamin & Pekerjaan \\
\hline 1. & $\mathrm{~N}$ & 15 & SMP & $\mathrm{P}$ & IRT \\
\hline 2. & $\mathrm{~W}$ & 15 & $\mathrm{SD}$ & $\mathrm{P}$ & IRT \\
\hline 3 & $\mathrm{E}$ & 16 & SMA & $\mathrm{P}$ & IRT \\
\hline 4. & $\mathrm{~W}$ & 16 & SMK & $\mathrm{P}$ & IRT \\
\hline 5. & $\mathrm{~S}$ & 17 & $\mathrm{SD}$ & $\mathrm{P}$ & IRT \\
\hline 6. & $\mathrm{E}$ & 15 & $\mathrm{SD}$ & $\mathrm{P}$ & IRT \\
\hline 7. & $\mathrm{~K}$ & 14 & $\mathrm{SD}$ & $\mathrm{P}$ & IRT \\
\hline 8. & $\mathrm{~A}$ & 13 & $\mathrm{SD}$ & $\mathrm{P}$ & IRT \\
\hline 9. & $\mathrm{R}$ & 17 & $\mathrm{SMK}$ & $\mathrm{P}$ & Pelajar \\
\hline 10. & $\mathrm{~F}$ & 50 & $\mathrm{SD}$ & $\mathrm{P}$ & Orang Tua \\
\hline
\end{tabular}

Ada beberapa faktor yang menyebabkan diadakannya Ritual Pammungkara jodoh antara lain:

a. Budaya

Sebagaimana yang dikatakan informan.

"Alasan saya melakukan ritual seperti pammungkara jodoh, awal mulanya ini dilakukan oleh nenek saya dan dilanjutkan oleh ibu saya dan sekarang saya yang melanjutkan ritual ini, ilmunya ini turun temurun dan saya juga akan wariskan ke anak saya ini adalah budaya yang turun temurun yang tidak ada habisnya, saya melakukan bagi orang yang percaya dan datang kepada saya dengan tidak ada keraguan, karena jika yang datang itu penuh kepercayaan maka targetnya akan cepat dicapai, saya melakukan ini semua karena petunjuk juga dan rahmat dari ALLAH SWT, mungkin lewat doa dan tangan saya, saya bisa membantu orang orang yang lagi sakit" ( S (58 tahun), 20 April 2020 )

b. Kurangnya Pengetahuan sebagaimna yang diungkapkan bahwa: "Saya masih ingin menikmati masa remaja saya, masih ingin berkumpul dengan teman teman saya, masih ingin jalan-jalan, dan masih ingin menikmati masa mudah saya, sayapun belum terlalu bisa berfikir baik-baik tetapi karena saya sudah disuruh menikah sama orang tua jadi saya ikut sja dari pada saya tidak menikah walau sebenarnya saya belum siap dan tidak mengetahui tentang pernikahan " $(\mathrm{M}$ (16 tahun), 26 April 2020)

c. Ekonomi

Didapat informasi bahwa: "Bagi keluarga saya, yang pasti siap memikul tanggung jawab terutama mengenai kebutuhan sehari-hari, umur bukanlah kendala, karena kami berasal dari orang yang tidak mampu, setelah saya menikah orang tua saya sudah tidak akan khawatir dan kepikiran terus kak (Wawancara, tanggal 8 Mei 2020).

d. Agama/keyakinan

Seperti yang informan katakan bahwa: "Saya sangat menyembah Allah SWT, tidak ada Tuhan selain Allah. Saya memandikan orang nak, dengan niat menolong sikamaseangki parangta tau, kupala mae rikaraeng ALLA taala punna nakamaseangki nakabulkanngi kanakke kupala battu rate tonji nak, saya nak tidak kusuruh orang datang sama saya, orang sendiri yang datang sama saya minta bantuan dan saya membantu nak parangta tau, saya sudah tua dan lamami ini saya kerjakan nak selama ini Alhamdulillah masih diberi rahmat sama yang di atas, ada semua nak syarat-syaratnya 
pada saat melakukan ritual/ memandikan nak, tidak sembarangan orang dan tempat ada waktu kususnya, pada zaman dulu nak yang melakukan ritual ini adalah orang tuaku dulu biar lagi tidak dimandiki cepatji menikah, tapi entah apa kajarian pernah dulu berawal dari almarhum sepupuku tidak menikah diumur 14 tahun, dimandi sama orang tuaku waktu itu tidak cukup 10 hari ada yang datang kerumahnya, semua berawal dari situ sampai saat ini masih diperlakukan itu nak, Alhamdulillah selama ini yang saya kalau saya doakan nak Inysa Allah selalu dikabulkan sama Allah nak, karena saya juga sholatku yang 5 waktu tidak pernah saya tinggalkan nak" (Ucap Sanro, 14 Mei 2020 )

Terjemahannya:

"Saya sangat taat beribadah kepada Allah SWT, tidak ada Tuhan selain Allah. Saya memandikan orang nak, dengan niat menolong sesama manusia, semoga Allah SWT mengasihi kita mengabulkan permohonan kita nak. Saya tidak menyuruh orang datang ke saya, mereka sendiri yang datang meminta bantuan saya dan saya membantu mereka. Saya sudah tua, sudah lama saya kerjakan nak dan selama ini Alhamdulillah saya masih diberi rahmat oleh Allah SWT. Semua nak ada syarat-syaratnya pada waktu melakukan ritual/memandikan nak. Tidak sembarangan orang dan tempat, ada waktunya khusus. pada zaman dahulu nak, yang melakukan ritual ini adalah orang tuaku. Dulu biar tidak dimandikan tetap cepat menikah, tapi entah kenapa ada kejadian di masa lalu yang bermula dari almarhum sepupuku tidak menikah diusia 14 tahun, kemudian dimandikan oleh orang tuaku pada waktu itu. Tidak lebih dari 10 hari setelah itu ada yang melamarnya. Semuanya berawal dari itu dan sampai saat ini masih dilakukan nak.

Alhamdulillah selama ini, yang saya doakan nak, Inysa Allah selalu dikabulkan oleh Allah SWT nak, karena saya jaga sholatku lima waktuku dan tidak pernah saya tinggalkan nak" (Ucap Dukun, 14 Mei 2020 )

\section{PEMBAHASAN}

Berdasarkan wawancara yang telah dilakukan pada bulan Mei 2020 dengan mereduksi data dan menyajikan data lalu menyimpulkan, maka terungkaplah permasalahan yang terjadi sehingga peneliti dapat menceritakan kembali hasil penelitian tersebut dalam sebuah karya tulis ilmiah dengan pendekatan kualitatif. Adapun permasalahan yang ditemukan oleh peneliti dilapangan yaitu ada beberapa faktor yang menyebabkan remaja melakukan ritual pammungkara jodoh terhadap pernikahan dini antara lain:

a) Budaya

Faktor budaya yang masih sangat erat di desa tersebut yang mempercayai sanro dan itu sudah bersifat turun temurun remaja melakukan ritual pammungkara jodoh terhadap pernikahan dini di Kabupaten Jeneponto adalah faktor budaya, yang harus putus sekolah dan mengorbankan masa remajanya, di Jeneponto khususnya dikampung Desa Maccini Baji masyarakat-masyarakat disana mempercayai bahwasanya jika menolak lamaran dari kaum laki laki maka anaknya tersebut tidak akan menikah lagi, dari hal tersebut juga menjadi pemicu dari pernikahan dini dikampung, sebagian juga dari orang tua remaja sudah merasa panik jika anaknya sudah berumur 15 ke atas belum menikah. (9) Pada masyarakat tradisional peran dukun dalam aspek sosial budaya seringkali lebih dominan dibandingkan peran tenaga kesehatanse hingga bisa dipahami bahwa masingmasing budaya masyarakat memiliki 
perspektifnya sendiri dan berpengaruh terhadap perilaku sosialnya, oleh sebab itu faktor budaya sebaiknya mendapat perhatian dari pengambil kebijakan bidang kesehatan terkait (3)

b) Kurangnya pengetahuan

Rendahnya pendidikan masyarakat mempengaruhi pengetahuan yang kurang tentang bahayanya dalam hal pernikahan dini, sebab dan akibat dalam kasus tersebut Orang tua menikahkan anak yang masih usia dibawah umur (10) tidak hanya karena keadaan ekonomi yang kurang mampu, tetapi rendahnya kesadaran orang tua terhadap pentingnya pendidikan anak pun menjadi salah satu pemicu berlangsungnya sebuah perkawinan (11). Pendidikan orang tua yang hanya lulus Sekolah Dasar (SD) bahkan ada juga yang tidak sekolah sama sekali (buta huruf) dengan mudahnya untuk segera melangsungkan sebuah penikahan kepada anak-anaknya. Karena orang tua yang kurang mengerti ataupun memahami sebuah perkawinan yang ideal, orang tua yang hanya lulus Sekolah Dasar (SD) atau tidak sekolah sama sekali (buta huruf) ia hanya melihat anak yang sudah besar sehingga ia berfikir sudah waktunya untuk menikah. Orang tua menikahkan anak karena mereka kurang mengerti ataupun faham tentang seluk beluk sebuah perkawinan yang ideal. Ia hanya melihat anak sudah besar atau sudah kelihatan dewasa, ia pikir hal seperti itu sudah cukup untuk melangsungkan sebuah perkawinan. Begitu juga dengan anak yang hanya lulus sekolah dasar atau yang masih dalam kondisi belajar baik pada bangku sekolah dasar ataupun pada bangku sekolah menengah pertama, belum begitu luas tentang pendidikan dan pengetahuan yang dimiliki, apalagi mengerti ataupun paham sebuah perkawinan yang ideal, sehingga mau untuk dinikahkan karena masih menuruti sama orang tua, orang tua menginginkan menikahkannya, sebagai seorang anak tidak menolaknya. Dengan anaknya menikah orang tua merasa senang dan bahagia. (12)

c) Ekonomi

Faktor ekonomi menjadi faktor klasik yang membuat remaja melakukan pernikahan dini di Desa Maccini Baji Kabupaten Jeneponto. Faktor ekonomi secara operasionalnya adalah sulit. Memenuhi kebutuhan hidup mereka sehari-hari. Sulitnya memenuhi kebutuhan ekonomi dan pendidikan membuat masyarakat, orang tua mengabaikan norma-norma dan aturan yang berlaku. Dan salah satu yang melatar belakangi yakni berasal dari keluarga dengan perekonomian menengah kebawah yang tidak mempunyai pendapatan tetap hanya mengharapkan hasil bumi untuk dikelola. Karena berasal dari keluarga tidak mampu hal ini sesuai dengan pendapat (Kartini Kartono, 2009). Bahwa tekanan ekonomi, faktor kemiskinan ada pertimbanganpertimbangan ekonomis untuk mempertahankan kelangsungan hidupnya, khususnya dalam mendapatkan status sosial yang baik tentunya menjadi sebuah keinginan bagi semua wanita.(13)

Faktor kesulitan ekonomi, ada pertimbangan-pertimbangan ekonomis untuk mempertahankan kelangsungan hidupnya menjadi hal yang mendorong seseorang. Terlepas dari permasalahan ekonomi menurut penulis melakukan perbuatan seperti di atas perlu mendapatkan perhatin khusus dari pihak yang terkait termasuk penegak hukum dan semua lapisan masyarakat yang sadar atas masa depan generasi bangsa karena praktek tersebut tak luput melibatkan pemuda penerus bangsa ini karena jika semua melakukan pernikahan dini lantas siapa yang akan menjadi penerus dimasa depan. (14) 
d) Agama

Ketika agama dilihat dan diperlakukan sebagai kebudayaan, maka yang terlihat adalah agama sebagai keyakinan yang ada dan hidup dalam masyarakat manusia, bukan agama yang terwujud sebagai petunjuk, larangan, dan perintah Allah SWT yang ada di dalam Al-Qur'an dan Hadis Nabi Muhammad SAW. Agama yang tertuang di dalam dua teks suci tersebut bersifat sakral dan universal, sedangkan keyakinan keagamaan yang hidup di masyarakat itu bersifat lokal, yaitu sesuai dengan kondisi, sejarah lingkungan hidup, dan kebudayaan masyarakatnya (15)

Adat atau tradisi yang berlaku di Dusun Pammisorang Kecamatan Batang Kabupaten Jeneponto, mereka

\section{UCAPAN TERIMA KASIH}

Penulis ingin menyampaikan ucapan terima kasih kepada pembimbing, KUA Kecamatan Batang, Kepala Desa Maccini Baji Kabupaten Jeneponto, dan Responden Penelitian yang telah bersedia untuk berpartisispasi tanpa adanya paksaan dari pihak manapun

\section{KESIMPULAN}

1. Budaya/adat merupakan salah satu hal yang memicu terjadinya ritual pammungkara jodoh terhadap pernikahan dini di Kabupaten Jeneponto, masyarakat setempat sudah percaya ritual tersebut secara turun temurun, masyarakat percaya akan ilmu/kekuatan yang dimiliki oleh sanro/dukun dan sebagian masyarakat yang masih mempertahankan budaya sehingga faktor Siri' (malu) menjadi alasan mengapa orang tua mengingingkan pernikahan dini anaknya.

2. Pendidikan juga mempengaruhi terjadinya ritual pammungkara jodoh, rendahnya tingkat pendidikan masyarakat setempat sehingga kurang pengatahuan akan pentingnya masa mempercayai seorang dukung/Sanro yang ada di kampung tersebut karena sudah lama melakukan Ritual seperti pammungkara jodoh agar cepat menikah dan memang adanya, sebagian masyarakat disana mempercayai bahwa ritual seperti itu ada dan terbukti adanya dan keberadaannya sudah lama.

Namun demikian, pemahaman hubungan antara budaya dengan agama tetap tidak bisa dipisahkan dari pemahaman normatif agama itu sendiri, yaitu agama dalam bentuk larangan dan perintah. Pemahaman normatif menjadi titik tolak untuk memahami bagaimana budaya memperkaya nilai normatif dan bagaimana nilai normatif dipraktikkan oleh masyarakat (16)

depan remaja. Selain itu, kurangnya pengetahuan masyarakat akan pentingnya pendidikan dan bahayanya dalam pernikahan di bawah umur.

3. Faktor ekonomi merupakan faktor yang paling utama, dimana pendapatan petani belum mampu sepenuhnya memenuhi kebutuhannya keluarga.

4. Kurangnya Pengetahuan Agama masyarakat membuat mereka percaya akan hal hal yang dilarang oleh agama seperti melakukan ritual pammungkara jodoh, masyarakat sendiri mempunyai pendapat yang berbeda beda tentang keyakinan kepada ALLAH SWT dan kepercayaan kepada manusia

\section{REFERENCY}

1. Jumatan Rate. 2017. Jurnal tradisi dan Perilaku Ritual Budaya Masyarakat Turatea Jeneponto. (6):58 -59

2. Najib. 2018. Tinjauan Yuridis Tentang Perkawinan Anak Di Bawah Umur Dan Akibat Hukumnya (Studi Kasus di Pengadilan Agama Sukoharjo). Diss. Universitas Muhammadiyah Surakrta.

3. Gobel, Fatmah Afrianty., A.M. Multazam., Andi Asrina, Ella 
Andayanie, 2019, An Overview of Socio-Cultural Factors on the Utilization of Antenatal Care Services in Bajonese Pomalaa, Southeast Sulawesi, Indian Journal of Public Health Research \& Development Vol. 10 No.10

4. Dewi. 2017. BPS Analisis Data Perkawinan Usia Dini di Indonesia. Jakarta: Badan Pusat Statistik.

5. Dwinanda, Aditya Risky, Anisa Catur Wijayanti, and Kusuma Estu Werdani. 2017. Hubungan Antara Pendidikan Ibu dan Pengetahuan Responden dengan Pernikahan Usia Dini. J. Kesehatan Masyarakat Andalas. Vol. 10. No. 1: 76-81.

6. Hasan, H. 2018. Pernikahan DI Bawah Umur (Analisis tentang Konsekuensi Pemidanaan). Al Daulah: J. Hukum Pidana dan Ketatanegaraan, Vol. 6. No. 1: 86-120

7. Mai, J. T. 2019. Tinjauan Yuridis terhadap Perkawinan Anak di Bawah Umur Dilihat dari Sudut Pandang Undang-Undang Nomor 1 Tahun 1974. Lex crimen, Vol. 8. No. 4.

8. Evita Yulivina, Fenti D. P., Ichayuen A. 2018. Faktor-Faktor yang Mempengaruhi Pernikahan Dini pada Pasangan Usia Subur (PUS) di Kelurahan Pasir Jaya Kecamatan Bogor Barat Kota Bogor Tahun 2018. promotor, Vol. 1.No. 1.

9. Mahfudin, Agus, Khoirotul Waqi'ah. 2016. Pernikahan Dini dan Budaya terhadap Keluarga di Kabupaten Sumenep Jawa Timur. J. Hukum Keluarga Islam, Vol 1. No. 1: 33-49.

10. Dwinanda, Aditya R., Anisa C. W., Kusuma E. W. 2017. Hubungan Antara Pendidikan Ibu dan Pengetahuan Responden dengan Pernikahan Usia Dini. J. Kesehatan Masyarakat Andalas Vol. 10.No.1: 76-81.

11. Jannah, Umi Sumbulah F. 2015. Pernikahan Dini dan Implikasinya terhadap Kehidupan Keluarga pada
Masyarakat (Perspektif Hukum Dan Gender)." EGALITA.

12. Khoirul Anam. 2019. Analisis alMaslahah al-Mursalah terhadap Program Sekolah Pra-Nikah oleh Pusat Pembelajaran Keluarga (PUSPAGA) di Surabaya. Diss. UIN Sunan Ampel Surabaya.

13. Kartono, K. 2005. Patologi Sosial Jilid II. Jakarta: Enreco.

14. Hanum, Y., \& Tukiman, T. 2015. Dampak Pernikahan Dini terhadap Kesehatan Alat Reproduksi Wanita. J. Keluarga Sehat Sejahtera, Vol. 13. No. 26.

15. Mahfudin, A., Khoirotul Waqi'ah. 2016. Pernikahan Dini dan Budaya terhadap Keluarga di Kabupaten Sumenep Jawa Timur." J. Hukum Keluarga Islam, Vol. 1. No. 1: 33-49.

16. Een Kurnaesih. 2019. Reproduksi Perpektif Islam. PIB Publishing Pemuda Indonesia Bangkit: 88-89.

17. Mai, J. T. 2019. Tinjauan Yuridis terhadap Perkawinan Anak di Bawah Umur Dilihat dari Sudut Pandang Undang-Undang Nomor 1 Tahun 1974. Lex crimen, Vol. 8. No. 4.

18. Muntamah, Ana Latifatul, Dian Latifiani, Ridwan Arifin. 2019. Pernikahan Dini di Indonesia: Faktor dan Peran Pemerintah (Perspektif Penegakan dan Perlindungan Hukum bagi Anak). Widya Yuridika, Vol. 2. No.1: 1-12.

19. Khairun Nisa, Hasibuan, H. A. L. Lubis, Z. M. 2019. Aspek Hukum Pencatatan Perkawinan menurut Hukum Indonesia di Desa Tumpatan Nibung Kecamatan Batang Kuis Kabupaten Deli Serdang. J. Ilmiah Penegakan Hukum, Vol 4. No. 2: 5059.

20. Badan Pusat Statistik. 2013. Survei Demografi dan Kesehatan Indonesia (SDKI). Jakarta: Badan Pusat Statistik 44: 122.

21. Saeful, Pupu R. 2012. Penelitian Kualitatif, 2012:

2-3 
